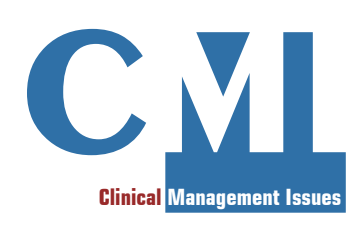

\title{
Statins and Immune-Mediated Necrotizing Myopathy
}

\begin{abstract}
Statins are a well-recognized cause of a variety of skeletal myopathic effects, which generally resolve when discontinuing the treatment. Among autoimmune manifestations associated with statins, there is immune-mediated necrotizing myopathy (IMNM).

The present article summarizes the main features of statin-related IMNM, describing diagnosis, classification, epidemiology, treatment, and the main autoantibodies detected.

Although it is impossible to define the precise number, it evident that more than 550 statinrelated IMNM cases have been described in the literature. Among IMNM, two forms must be distinguished: with anti-3-hydroxy-3-methylglutaryl-coenzyme A reductase (HMGCR) and with anti-signal recognition particle (SRP) antibodies. The differential diagnosis should be made between the IMNM and self-limited statin-related myopathy, drug-induced rhabdomyolysis, and nonautoimmune myopathies.

Patients who have failed to normalize high creatine phosphokinase (CPK) after statin withdrawal should be tested for anti-HMGCR antibodies and, if these are positive, undergo muscle biopsy to confirm the diagnosis of IMNM. Pharmacological therapy of IMNM, not yet based on evidence, involves the use of high-dose corticosteroids, immunosuppressant drugs used alone or in combination, intravenous immunoglobulins (IVIg) or plasmapheresis.
\end{abstract}

Keywords: Hydroxymethylglutaryl-CoA Reductase Inhibitors; Dermatomyositis; Polymyositis; Immune-mediated necrotizing myopathy; Anti-HMGCR antibodies

Statine e miopatia necrotizzante immuno-mediata

CMI 2018; 12(1): 77-88

https://doi.org/10.7175/cmi.v12i1.1367

\section{STATINS}

Statins are among the most widely prescribed drugs. They helped increase the survival rate in patients affected by cardiovascular disease.

Millions of prescriptions are written annually for this class of drugs. Therefore, it is of the utmost importance to closely monitor patients for adverse and even life-threatening side effects.

The most common side effects of statins include the development of toxic myopathies, which usually resolve after drug removal (about 2-20\% of patients treated with statins [1]). The risk of statin myopathy and/ or increased creatine phosphokinase (CPK) is dose-dependent.

Statin-related muscle side effects have recently been systematically classified [2]: as SRM 6 class it is possible to find the rarest among muscle side effects, those concerning autoimmune phenomena (Table I).

In fact, recently, immune-mediated necrotizing myopathy (IMNM) has been found to be sometimes associated with statin use.

In addition, exposure to statins was reported in some cases of inflammatory myopathies such as polymyositis (PM) and dermatomyositis (DM). The association of statins and PM or DM is sustained by some authors, and criticized by others, who believe that these cases could be IMNM.
Former Department of Internal Medicine, Ospedali Riuniti Padova Sud, Monselice (Padova), Italy

Corresponding author Dr. Mauro Turrin Monselice-Padova Tel. +39 328.9032440 m.turrin@libero.it

Received: 11 July 2018 Accepted: 18 October 2018 Published: 25 October 2018 
Table I. Statin-related myotoxicity phenotype classification. Modified with permission to reuse from [2]

$\mathrm{CPK}=$ creatin

phosphokinase;

HMGCR = 3-hydroxy-3-

methylglutaryl-coenzyme A

reductase;

$\mathrm{SRM}=$ statin-related

myotoxicity;

ULN = upper limit

of normal

\begin{tabular}{|c|c|c|c|}
\hline $\begin{array}{c}\text { SRM } \\
\text { Blassification }\end{array}$ & Phenotype & Definition & Incidence \\
\hline SRM 0 & $\begin{array}{l}\text { CPK elevation }<4 \mathrm{x} \\
\text { ULN }\end{array}$ & No muscle symptoms & $1.5-26 \%$ \\
\hline SRM 1 & Myalgia, tolerable & Muscle symptoms without CPK elevation & $0.3-33 \%$ \\
\hline SRM 2 & Myalgia, intolerable & $\begin{array}{l}\text { Muscle symptoms, CPK }<4 \text { x ULN, complete } \\
\text { resolution on dechallenge }\end{array}$ & $0.2-2 / 1000$ \\
\hline SRM 3 & Myopathy & $\begin{array}{l}\text { CPK elevation }>4 \times \text { ULN with or without } \\
\text { muscle symptoms, complete resolution on } \\
\text { dechallenge }\end{array}$ & $\begin{array}{l}\text { 5/100,000 } \\
\text { patient-years }\end{array}$ \\
\hline SRM 4 & Severe myopathy & $\begin{array}{l}\text { CPK elevation }>10 \times \text { ULN }<50 \times \text { ULN, } \\
\text { muscle symptoms, complete resolution on } \\
\text { dechallenge }\end{array}$ & $0.11 \%$ \\
\hline SRM 5 & Rhabdomyolysis & $\begin{array}{l}\text { CPK elevation }>10 \times \text { ULN with evidence of } \\
\text { renal impairment }+ \text { muscle symptoms or CPK } \\
>50 \times \text { ULN }\end{array}$ & $\begin{array}{c}0.1-8.4 \\
/ 100,000 \\
\text { patient-years }\end{array}$ \\
\hline SRM 6 & $\begin{array}{l}\text { Autoimmune-mediated } \\
\text { necrotizing myositis }\end{array}$ & $\begin{array}{l}\text { HMGCR antibodies, HMGCR expression in } \\
\text { muscle biopsy, incomplete resolution on } \\
\text { dechallenge }\end{array}$ & $\begin{array}{l}\sim 2 / \text { million } \\
\text { per year }\end{array}$ \\
\hline
\end{tabular}

\section{CLASSIFICATION AND DIAGNOSTIC CRITERIA}

In 2003, in the Netherlands the category of immune-mediated necrotizing myopathy (IMNM) was introduced for the first time by the European Neuromuscular Centre Workshop [3].

In 2017, the European League Against Rheumatism/American College of Rheumatology (EULAR/ACR) defined the classification criteria of inflammatory myopathies (IIMs) [4].

In the same year an integrated classification of inflammatory myopathies, authored by Allenbach and colleagues [5], was published. Unlike the EULAR classification, the difference between PM, a very uncommon isolated disease, and IMNM was well defined.

$\begin{array}{ll}\text { Abbreviations of Autoantibodies } \\ \text { HMGCR } & \text { 3-hydroxy-3-methylglutaryl-coenzyme A reductase } \\ \text { Jo1 } & \text { bistidyl-tRNA synthetase } \\ M D A 5 & \text { melanoma differentiation-associated gene } 5 \\ \text { NXP2 } & \text { nuclear matrix protein } 2 \\ \text { PL7 } & \text { threonyl-tRNA synthetase } \\ \text { PL12 } & \text { alanyl-tRNA synthetase } \\ \text { Pm/Scl } & \text { anti-polymyositis-scleromyositis } \\ \text { SAE } & \text { small ubiquitin-like modifier activating enzyme } \\ S R P & \text { signal recognition particle } \\ \text { TIF1 } & \text { transcription intermediary factor } 1 \\ U 1 R N P & \text { U1 ribonucleoprotein }\end{array}$

In September 2018, Selva-O'Callaghan and colleagues published on Lancet Neurology a new classification of inflammatory myopathies in the adult based on the clinical characteristics of the main clinical and phenotype-specific autoantibody groups [6]. Five main types of IIM are recognized:

- Dermatomyositis (with autoantibodies against Mi2, NXP2, TIF1, SAE, MDA5 or no autoantibodies detected), affecting mainly skin and muscle;

- Immune-mediated necrotizing myopathy (with autoantibodies against SRP, HMGCR or no autoantibodies detected), affecting mainly muscle in a severe manner;

- Sporadic inclusion-body myositis, affecting muscle severely;

- Overlap myositis (including antisynthetase syndrome, where autoantibodies against Jo1, PL7, and PL12 may be detected, and three other forms, with autoantibodies against $\mathrm{Pm} / \mathrm{Scl}, \mathrm{Ku}$, and U1RNP), affecting mainly muscle and lung; and

- Polymyositis, with heterogeneous clinical features.

Many patients previously classified as having PM could now be considered to have antisynthetase syndrome without a rash, IMNM or sporadic inclusion-body myositis: the condition remains a diagnosis of exclusion. 


\begin{tabular}{|c|c|}
\hline $\begin{array}{l}\text { Muscle } \\
\text { symptoms }\end{array}$ & $\begin{array}{l}\text { Subacute, progressive, symmetrical, proximal muscle weakness (especially posterior } \\
\text { thigh, medial thigh, and gluteal compartments) }\end{array}$ \\
\hline CK & $\begin{array}{l}\text { Increased (6000-10,000; range: } 1000-50,000) \text { and persistent despite statins } \\
\text { discontinuation }\end{array}$ \\
\hline EMG & $\begin{array}{l}\text { Myogenic pattern (usually with spontaneous activity in the form of fibrillations and } \\
\text { positive sharp waves) }\end{array}$ \\
\hline MRI & $\begin{array}{l}\text { Muscle edema, extensive necrosis, atrophy, fatty replacement, fascial edema, minimal } \\
\text { or absent inflammation } \\
\text { T1 hyperintensity especially in posterior thigh; STIR signal is increased and may be } \\
\text { asymmetric }\end{array}$ \\
\hline Risk factors & Statin drugs or supplements \\
\hline $\begin{array}{l}\text { Specific } \\
\text { immunogenetic } \\
\text { background }\end{array}$ & $\begin{array}{l}\text { Adult: HLA-DRB1*11:01 allele } \\
\text { Children: HLA-DRB1*07:01 allele }\end{array}$ \\
\hline Muscle biopsy & $\begin{array}{l}\text { Necrotizing myopathy } \\
\text { Granular complement C5b-9 (MAC) deposition on the sarcolemma of myofibers } \\
\text { Faint sarcolemmal MHC-I expression in non-necrotic/non-regenerating fibers }\end{array}$ \\
\hline Therapy & Sensitive to prolonged therapy with corticosteroids + immunosuppressants, IVIg \\
\hline
\end{tabular}

Table II. Diagnostic criteria for statininduced immunemediated necrotizing myopathy (IMNM) or statin-induced necrotizing autoimmune myopathy (SINAM). Modified from [14-17]

$\mathrm{CK}=$ creatine kinase;

$\mathrm{EMG}=$ electromyography; HMGCR = 3-hydroxy-3 methylglutaryl-coenzyme A reductase;

$\mathrm{IVIg}=$ intravenou

immunoglobulin;

$\mathrm{MAC}=$ membranolytic

attack complex;

$\mathrm{MHC}=$ major

histocompatibility complex class I antigen;

MRI = magnetic resonance imaging;

STIR = short-tau inversion recovery sequences in MRI

Besides clinical criteria, magnetic resonance imaging (MRI) $[3,7]$ can be useful to make the right diagnosis.

Statins have also been implicated in other autoimmune diseases, such as interstitial lung disease, myasthenia gravis, systemic lupus erythematosus, cutaneous lupus, vasculitis, autoimmune hepatitis, and lichen planus pemphigoides [8-10].

Several cases appeared in recent years in literature related to necrotizing myopathies associated with statins and with the coexistence of autoimmune phenomena $[8,11]$.

In the list of rare diseases of Orphanet [12], immune-mediated necrotizing myopathy appears at n. 206569 and has several synonyms: anti-HMG-CoA myopathy, anti-SRP myopathy, autoimmune necrotizing myositis, IMNM, immune myopathy with myocyte necrosis, and necrotizing autoimmune myopathy (NAM).

The possible causes for the onset of IMNM are: statins, connective tissue diseases, or cancer.

Until June 2018, the presence of 300 cases of IMNM overall was reported in Orphanet list [12], instead until February 2018 a French communication cited 390 cases in adults and 20 pediatric cases [13].

Incidence of statin-related IMNM was estimated to be 2-3 new cases in every 100,000 patients exposed to statins, with age at onset ranging from adulthood to elderly [14].

Immune-mediated necrotizing myopathy is a serious muscle complication that may be associated with statin use and has recently been described. It has been defined after the discovery of anti-3-hydroxy3-methylglutaryl-coenzyme A reductase antibodies (anti-HMGCR). The characteristics of statin-related IMNM are described in Table II.

The positivity of anti-HMGCR antibodies defines the IMNM associated to them as "SINAM": statin-induced necrotizing autoimmune myopathy.

\section{EPIDEMIOLOGY}

I have recently described the clinical case [18] of an elderly woman with clinical manifestations suggestive for dermatomyositis/polymyositis: fatigue and progressive weakness for proximal deficit in the lower limbs, heliotrope rash on the face, erythema at the neck, back, and thighs, increase in CPK (peak 5968 IU/1) that did not regress with cortisone therapy, antinuclear antibody titer of 1:640 (fine speckled pattern), antiJo-1 negative, irritative proximal myopathy to EMG, muscle edema to the MRI of the pelvis and lower limbs. The patient had been taking statins for at least 12 years (pravastatin, then rosuvastatin).

This report, unfortunately not supported by the test for anti-HMGCR antibodies, has many similarities with the limited number of international case series [19-31] and with individual case reports described both before [32-40] and after the use of anti-HMGCR [41-66].

In Italy, there are only nine cases in reports [67-71] of probable IMNM. There are also 
5 cases anti-HMGCR positive included in two large international case series $[20,72]$.

In a European registry of 11 countries, 105 cases of IMNM are included in 3067 patients with myositis [72].

A comprehensive systematic review of 100 published case reports and case series of patients with statin-associated autoimmune myopathy was written last year by American Authors [73].

The communications presented in 2018 relate so far to New Zealand [30] with the description of 4 cases: 2 males +2 females, age 59-77 years, long-term exposure to atorvastatin, CPK peak between 4.200 and $21.856 \mu \mathrm{mol} / 1$, high titer anti-HMGCR, myositis-associated autoantibodies (MAA) and myositis-specific autoantibodies (MSA) negative. Electromyography (EMG) reported myopathic changes, while MRI showed extensive muscle edema. Biopsy demonstrated the presence of prominent fiber necrosis with infiltrating macrophages. The patients were given therapies with corticosteroids, methotrexate, and intravenous immunoglobulin (IVIg). A previous clinical series of 8 patients was described in 2016 [74], giving an overall incidence in New Zealand of 1.7/ million/year although it has been estimated at 2 million/year in a US population.

Two additional cases in the USA $[75,76]$, one in Brazil [77], four cases in UK [78,79] and five cases in France [80] have been so far described in the literature in 2018.

The statin mainly implicated in the IMNM was usually high dose atorvastatin, followed by simvastatin, pravastatin, and fluvastatin. Rosuvastatin has been described in only 13 cases [19,22-24,41,61,81-84].

The high risk of neoplasia in autoimmune necrotizing myopathies has been reported [85].

Increasingly frequent, even if anecdotal, are the reports of the positivity of antiHMGCR in paraneoplastic necrotizing myopathy [77], especially in the Japanese population [83,86-88]: prevalence rates of cancer association (detected within 3 years of anti-HMGCR myopathy diagnosis) ranges from $4 \%$ to $36 \%$ and no specific type of cancer was observed [86].

\section{AUTOANTIBODIES}

There are two forms of IMNM respectively associated with positive anti-SRP and anti-HMGCR antibodies. These two antibodies were positive in $2 / 3$ of cases of autoimmune necrotizing myopathy.

The detection of these antibodies associated with thigh MRI defines the two subtypes that have different systemic and anatomical involvement, while muscle biopsy instead provides an identical result $[7,89,90]$.

\section{Anti-HMGCR}

In 2010 Cristopher-Stine and colleagues [91] found in the sera of patients with necrotizing myopathy of unknown etiology the presence of a pair of immunoprecipitates of molecular weight 200 and $100 \mathrm{kDa}$, not corresponding to those already known in the myositis. The autoantigens of these antibodies came from 3-hydroxy-3-methylglutarylcoenzyme A reductase with muscle expression. This autoantibody, directed against the pharmacologic target of statins, were termed "anti-HMGCR" [92-96].

Anti-HMGCR autoantibodies were specific for statin-related IMNM: the prevalence of statin exposure was between $40 \%$ and $92 \%$ in patients with these antibodies [20,22,24,27,29,92,94-99], whereas they were found positive only in small proportion in inflammatory myopathies $[20,24]$.

A 2015 Chinese study confirmed a low positivity $(5.4 \%)$ of anti-HMGCR in patients with IIMs [81]. A multicenter international research, published in 2016, has shown, in addition to a low prevalence in polymyositis $(4.4 \%)$ and in dermatomyositis (1.9\%), a high presence of such antibodies $(76.5 \%)$ in a population of elderly, aged $>50$ years, with IMNM exposed to statins [81].

They were also found in $30-50 \%$ of subjects not exposed to statins.

In patients with HMGCR antibodies and autoimmune myopathy but without statin exposure, including children $[13,22,100]$, other possible sources of statin exposure have been hypothesized in consumption of red yeast rice (Monascus purpureus, Monacolina K), Pu-erb tea (rich in Aspergillus terreus), food containing certain type of oyster mushrooms, and other molds and yeasts all natural sources of statins [1,101].

Pediatric anti-HMGCR positive cases were all negative for statin exposure [102] demonstrating that autoantibody may simply develop as an auto-immune reaction with an unknown trigger.

It is reported that in Asians the myopathy is not typically associated with statin use. 
A specific immunogenetic background in children is HLA-DRB1*07:01 [103] unlike DRB1*11:01 allele in adults.

Tests for anti-HMGCR by ELISA, currently limited to a few centers, presented high sensitivity (94\%) and high specificity (99\%).

Autoantibody levels are correlated with both creatine kinase and the degree of proximal muscle weakness $[22,92,95,98]$, to be considered a highly specific biomarker of disease.

HMGCR antibodies, although specific, do not appear to inhibit the target enzyme. This observation is consistent with the lack of specificity of the lipid profile [104].

The intake of atorvastatin and diabetes mellitus type 2 were the two most significant independent predictors for the onset of myopathy associated with anti-HMGCR $[105,106]$.

Anti-HMGCR antibodies persist even after cessation of statin therapy [107] and despite clinical improvement following immunosuppressive therapy.

\section{Anti-SRP}

Anti-SRP patients are weaker than antiHMGCR patients, suggesting that IMNM includes at least two distinct forms of myositis associated with these two autoantibodies.

In the anti-SRP positive IMNM, neurological symptoms and muscular involvement are present with limb and neck muscle weakness, dysphagia and respiratory failure, symptoms always present and more severe than the form with HMGCR positive $[89,108]$.

MRI in anti-SRP subjects detects a more extensive muscle atrophy and a higher adipose substitution, compared to antiHMGCR demonstrating that autoantibodies define precisely these two distinct clinical subgroups [59,109-111].

While anti-SRP and anti-HMGCR antibodies show a strong affinity for their antigenic target, affinity and clinical severity cannot be associated.

\section{DIFFERENTIAL DIAGNOSIS}

According to some Authors, the majority of patients with necrotizing myopathy with a history of statins before the discovery of anti-HMGCR were classified as polymyositis. The statin-triggered IMNM and polymyositis would therefore not be two distinct entities, but part of the same pathophysiological spectrum also because they respond well to immunosuppressive treatment $[19,112]$.

In addition, a genetic risk factor in adult subjects was established by the class II HLA allele DRB1*11: 01 [11]: it is strongly associated with the development of antiHMGCR antibodies, even in patients without known exposure to statins.

In the IMNM, magnetic resonance detects a characteristic pattern of muscular abnormalities involving mainly hip rotators and glutei: IMNM have significantly more widespread muscle edema, atrophy, and fatty replacement compared with those with polymyositis (PM) and dermatomyositis (DM), unlike the fascial edema is more common and widespread in dermatomyositis [7].

In the differential diagnosis of necrotizing myopathy, rhabdomyolysis produced by drugs should be excluded, in particular those responsible for the neuroleptic malignant syndrome.

The list of drugs causing muscle necrosis is long $[19,112,113]$, and cholesterol-lowering agents (statins, fibrates), the immunophilins cyclosporine and tacrolimus, nucleoside analogs (telbivudine and entecavir) and drugs causing neuroleptic malignant syndrome (NMS)[114-116] are among the more common ones.

In addition, alcohol intoxication (in binge drinking), cocaine and heroin are associated with muscle necrosis.

Snake venoms (rattlesnake and cobra) produce isolated muscle fiber necrosis and regeneration.

Nonautoimmune myopathies most frequently misdiagnosed as myositis in children include inherited dystrophy, due to relatively slow progression and myopathological similarity: dysferlinopathy (limb-girdle muscular dystrophy 2B-LGMD 2B), calpainopathy (LGMD 2A) and facio-scapulohumeral dystrophy (FSHD) $[22,77,100,117,118]$.

In the adult the differential diagnosis must be made with sporadic inclusion body myositis (sIBM), hypothyroid myopathy and severe self-limited statin myopathy [119].

Regarding statin myotoxicity, the main epidemiological studies have shown that neither statin myalgia nor CPK levels < 5 times upper limit of normal (ULN) and without muscle weakness are associated with the presence of anti-HMGCR [97,98].

In all cases of severe myopathy, but selflimited by the discontinuation of the statin, 
there was no positive finding for antiHMGR [120].Therefore, in these cases such antibodies should not be tested.

In the self-limited statin-related myopathy a genomewide association study revealed a strong association with a single nucleotide polymorphism (SNP) rs4363657 located within the SLCO1B1 (solute carrier organic anion transporter family, member 1B1) gene on chromosome 12 [11,121].

\section{TREATMENT}

Pharmacological therapy of IMNM, not yet based on evidence, involves the use of high-dose corticosteroids and immunosuppressant drugs used alone or in combination: methotrexate, azathioprine, mycophenolate mofetil, rituximab, cyclophosphamide, etanercept (results about its use are conflicting), abatacept, tocilizumab, tacrolimus and cyclosporine. In addition, intravenous immunoglobulins (IVIg) or plasmapheresis may be beneficial in case of severe manifestations of the disease [6].

In a lot of drugs, an initial induction therapy is required before maintenance therapy.

However, rigorous data from the literature are lacking: an international consensus regarding treatment recommendations for patients with anti-HMGCR and antiSRP myopathies has recently been presented [17] for the use of steroids, methotrexate, IVIg and rituximab together with a review in 2018 [6] where the treatment of severe manifestations of the disease was described.

\section{CONCLUSIONS}

Even though it is a rare phenomenon (around 550 cases described in the literature), statins may cause an autoimmune disease called "statin-related immune-mediated necrotizing myopathy". It is characterized by progressive rhabdomyolysis with intense

\section{Practical Applications}

- Patients taking high dose statins, over the age of 50, who develop myopathy with muscular asthenia associated with increased $C P K>5$ times the upper limit are at risk of developing autoimmune necrotizing myopathy

- In subjects taking statins, testing for anti-HMGCR autoantibodies may belp to discriminate between self-limited rhabdomyolysis and statin-associated autoimmune myopathy

- In myopathic patients positive for anti-HMGCR, especially in the elderly, it is necessary to verify the coexistence of neoplasia

- Patients who have failed to normalize high CPK (> 10 times the upper range of normal) after statin withdrawal and after cortisone therapy should be tested for anti-HMGCR antibodies and, if these are positive, undergo muscle biopsy to confirm the diagnosis of IMNM

Key Points

- Statin intolerance is the main reason for discontinuing therapy for hypercholesterolemia associated with or without cardiovascular disease

- Besides the known side effects on muscle, statins can cause autoimmune phenomena

- A rare but serious complication is progressive rhabdomyolysis with intense and widespread muscular impairment that does not respond to drug withdrawal

- This new entity, called statin-related IMNM, is associated with the presence of autoantibodies against 3-hydroxy-3-methyl-glutaryl-CoA reductase, a key enzyme in the synthesis of inbibited cholesterol by statins

- The diagnosis is addressed by the positivity of these antibodies and confirmed by muscle biopsy

- Exclusion of more common endocrine, genetic, and metabolic myopathies is essential

- Inflammatory myopathies are a very heterogeneous group of illnesses that can present with a very different clinical phenotype

- Drug therapy, not yet subject to guidelines, is challenging and requires, in addition to corticosteroids, immunosuppressive medications, and often immunoglobulins, and plasmapheresis

- The international literature has reported around 550 statin-associated IMNM 
and widespread muscular impairment and doesn't respond to drug withdrawal. $\mathrm{Au}-$ toantibodies against HMGCR may be detected. The diagnosis is challenging and the treatment, not yet regulated by guidelines, is generally based on corticosteroids and immunosuppressants.

On the basis of the cases described and literature review some practical applications may be summarized.

Funding

This article has been published without the support of sponsors.

Conflicts of interests

The Author declares that he has no conflicts of financial interest regarding the topics covered in this article.

\section{REFERENCES}

1. Selva-O'Callaghan A,Alvarado-Cardenas M,Pinal-Fernández I, et al. Statin-induced myalgia and myositis: an update on pathogenesis and clinical recommendations. Expert Rev Clin Immunol 2018;14: 215-24; https://doi.org/10.1080/1744666X.2018.1440206

2. Alfirevic A, Neely D, Armitage J, et al. Phenotype standardization for statin-induced myotoxicity. Clin Pharmacol Ther 2014; 96: 470-6; https://doi.org/10.1038/clpt.2014.12

3. Hoogendijk JE,Amato AA, Lecky BR et al.119th ENMC international workshop: trial design in adult idiopathic inflammatory myopathies, with the exception of inclusion body myositis, 10-12 October 2003, Narden, The Nederlands. Neuromuscul Disord 2004; 14: 337-45. https:// doi.org/10.1016/j.nmd.2004.02.006

4. Lundberg IE, Tjärnlund A, Bottai M, et al; International Myositis Classification Criteria Project consortium, The Euromyositis register and The Juvenile Dermatomyositis Cohort Biomarker Study and Repository (JDRG) (UK and Ireland). 2017 European League Against Rheumatism/American College of Rheumatology classification criteria for adult and juvenile idiopathic inflammatory myopathies and their major subgroups. Ann Rheum Dis 2017; 76: 1955-64; https://doi.org/10.1136/annrheumdis-2017-211468

5. Allenbach $\mathrm{Y}$, Benveniste $\mathrm{O}$, Goebel $\mathrm{HH}$, et al. Integrated classification of inflammatory myopathies. Neuropathol Appl Neurobiol 2017; 43: 62-81; https://doi.org/10.1111/nan.12380

6. Selva-O'Callaghan A, Pinal-Fernandez I, Trallero-Araguás E, et al. Classification and management of adult inflammatory myopathies. Lancet Neurol 2018; 17: 816-28; https://doi. org/10.1016/S1474-4422(18)30254-0

7. Pinal-Fernandez I, Casal-Dominguez M, Carrino JA, et al. Thigh muscle MRI in immunemediated necrotising myopathy: extensive oedema, early muscle damage and role of antiSRP autoantibodies as a marker of severity. Ann Rheum Dis 2017; 76: 681-7; http://dx.doi. org/10.1136/annrheumdis-2016-210198

8. Padala S, Thompson PD. Statins as a possible cause of inflammatory and necrotizing myopathies. Atherosclerosis 2012; 222: 15-21; https://doi.org/10.1016/j.atherosclerosis.2011.11.005

9. Noël B. Lupus erythematosus and other autoimmune diseases related to statin therapy: a systematic review.J Eur Acad Dermatol Venereol 2007; 21: 17-24; https://doi.org/10.1111/j.14683083.2006.01838.x

10. Turrin M, Martinelli S. Drug-induced lupus: simvastatin or amiodarone? A case report in elderly. Clinical Management Issues 2013; 7: 17-26; https://doi.org/10.7175/cmi.v7i1.644

11. Mohassel P, Mammen AL. Statin-associated autoimmune myopathy and anti-HMGCR autoantibodies. Muscle Nerve 2013; 48: 477-83; https://doi.org/10.1002/mus.23854

12. Orphanet. Elenco delle malattie rare e sinonimi: in ordine alfabetico. I Quaderni di Orphanet. June 2018. Available at www.orpha.net/orphacom/cahiers/docs/IT/Elenco_malattie_rare_in_ ordine_alfabetico.pdf (last accessed October 2018)

13. Aubignat $\mathrm{M}, \mathrm{Schmidt} \mathrm{J}$, Gourguechon $\mathrm{C}$, et al. Myopathies à anticorps anti-HMGCR : à propos de 5 cas. La Revue de Médecine Interne 2018; 39 (Suppl 1): A227-A228; https://doi. org/10.1016/j.revmed.2018.03.225

14. Mammen AL. Statin-associated autoimmune myopathy. $N$ Engl J Med 2016; 374: 664-9; https://doi.org/10.1056/NEJMra1515161 
15. Albayda J, Christopher-Stine L. Identifying statin-associated autoimmune necrotizing myopathy. Cleve Clin J Med 2014; 81: 736-41; https://doi.org/10.3949/ccjm.81a.13158

16. Mohassel P,Mammen AL.Anti-HMGCR myopathy.JNeuromuscul Dis 2018; 5: 11-20; https:// doi.org/10.3233/JND-170282

17. Allenbach Y, Mammen AL, Benveniste O, et al; Immune-Mediated Necrotizing Myopathies Working Group. 224th ENMC International Workshop: Clinico-sero-pathological classification of immune-mediated necrotizing myopathies Zandvoort, The Netherlands, 14-16 October 2016. Neuromuscul Disord 2018; 28: 87-99; https://doi.org/10.1016/j.nmd.2017.09.016

18. Turrin M, Martinelli S. Statin-induced rhabdomyolysis: polymyositis/dermatomyosytis or necrotizing autoimmune myopathy? Description of a clinical case in an elderly patient. Giornale Italiano dell'Arteriosclerosi 2017; 8: 83-8

19. Wu Y, Lach B, Provias JP, et al. Statin-associated autoimmune myopathies: A pathophysiologic spectrum. Can J Neurol Sci 2014; 41: 638-47; https://doi.org/10.1017/cjn.2014.22

20. Musset L, Allenbach Y, Benveniste O, et al. Anti-HMGCR antibodies as a biomarker for immune-mediated necrotizing myopathies: A history of statins and experience from a large international multi-center study. Autoimmun Rev 2016; 15: 983-93; https://doi.org/10.1016/j. autrev.2016.07.023

21. Ohnuki Y, Suzuki S, Shiina T, et al. HLA-DRB1 alleles in immune-mediated necrotizing myopathy. Neurology 2016; 87: 1954-5; https://doi.org/10.1212/WNL.0000000000003160

22. Allenbach $Y$, Drouot L, Rigolet A, et al; French Myositis Network. Anti-HMGCR autoantibodies in European patients with autoimmune necrotizing myopathies: inconstant exposure to statin. Medicine (Baltimore) 2014; 93: 150-7; https://doi.org/10.1097/MD.0000000000000028

23. Meira Dias O, Guedes Baldi B, Nathan Costa A, et al. Interstitial lung disease with statinassociated necrotizing autoimmune myopathy responding to rituximab. Arch Bronconeumol 2016; 52: 395-7; https://doi.org/10.1016/j.arbres.2015.10.011

24. Klein M, Mann H, Pleštilová L, et al. Increasing incidence of immune-mediated necrotizing myopathy: single-centre experience. Rheumatology (Oxford) 2015; 54: 2010-4; https://doi. org/10.1093/rheumatology/kev229

25. Ramanathan S, Langguth D, Hardy TA, et al. Clinical course and treatment of anti-HMGCR antibody-associated necrotizing autoimmune myopathy. Neurol Neuroimmunol Neuroinflamm 2015; 2: e96; https://doi.org/10.1212/NXI.0000000000000096

26. Alshehri A, Choksi R, Bucelli R, et al. Myopathy with anti-HMGCR antibodies: Perimysium and myofiber pathology. Neurol Neuroimmunol Neuroinflamm 2015; 2: e124; https://doi. org/10.1212/NXI.0000000000000124

27. Grable-Esposito P, Katzberg HD, Greenberg SA, et al.Immune-mediated necrotizing myopathy associated with statins. Muscle Nerve 2010; 41: 185-90; https://doi.org/10.1002/mus.21486

28. Kassardjian CD, Lennon VA, Alfugham NB, et al. Clinical features and treatment outcomes of necrotizing autoimmune myopathy.JAMA Neurol 2015; 72: 996-1003; https://doi.org/10.1001/ jamaneurol.2015.1207

29. Ashton C, Junckerstorff R, Bundell C, et al. Treatment and outcomes in necrotising autoimmune myopathy: An Australian perspective. Neuromuscul Disord 2016; 26: 734-40; https://doi. org/10.1016/j.nmd.2016.08.013

30. Woolley M, Stebbings S, Highton J. Statin-associated immune-mediated necrotising myopathy: a New Zealand case series showing possible overrepresentation in Pacific Islanders. Intern Med J 2018; 48: 32-6. https://doi.org/10.1111/imj.13575

31. Waters MJ, Limaye V. Clinico-serologic features of statin-induced necrotising autoimmune myopathy in a single-centre cohort. Clin Rheumatol 2018; 37: 543-7; https://doi.org/10.1007/ s10067-017-3831-2

32. Folzenlogen D. A case of atorvastatin combined toxic myopathy and inflammatory myositis. $J$ Clin Rheumatol 2001; 7: 340-5; https://doi.org/10.1097/00124743-200110000-00019

33. Young JB, Ghobrial II. Autoimmune statin-induced myopathy: a case report. J Community Hos $p$ Intern Med Perspect 2015; 5: 28374; https://doi.org/10.3402/jchimp.v5.28374

34. Rugiero M, Bettini M, Bisonni A, et al. P5.24 Immune-mediated Necrotizing Myopathy Associated with Statins: Presentation of two cases and review of the literature. Neuromuscul Disord 2011; 21: 731; https://doi.org/10.1016/j.nmd.2011.06.1053

35. Scripko PD, Amato AA, Puig A.Mystery case: a 63-year-old man with progressive proximal pain and weakness. Neurology 2014; 82: e26-9; https://doi.org/10.1212/WNL.0000000000000052

36. Patel S, Rohatgi A, Gupta P. Statin-triggered immune-mediated necrotizing myopathy. Neurol India 2016; 64: 562-4; https://doi.org/10.4103/0028-3886.181571 
37. Ogando S, Fischer H, Mailloux L, et al. Immune Mediated Necrotizing Myopathy case series [abstract]. Journal of Hospital Medicine 2014; 9 (suppl 2). Abstract number: 545

38. Fernandes GH, Zanoteli E, Shinjo SK. Statin-associated necrotizing autoimmune myopathy. Mod Rheumatol 2014; 24: 862-4; https://doi.org/10.3109/14397595.2013.874739

39. Kuncova K, Sedlackova M, Vencovsky J, et al. Inflammatory myopathy associated with statins: report of three cases. Mod Rheumatol 2014; 24: 366-71; https://doi.org/10.3109/14397595.2 013.852848

40. Khattri S. Statin-associated necrotizing myopathy in an older woman.J Musculoskel Med 2012; 29: $112-13$

41. Vijiaratnam N, Jiang M, Wijeratne T. Statin-associated autoimmune myopathy: diagnostic challenges. American Research Journal of Medicine and Surgery 2015; 1: 7-9

42. Mygland Å, Ljøstad U, Krossnes BK. Persisting weakness after withdrawal of a statin. BMJ Case Rep 2014; 2014; https://doi.org/10.1136/bcr-2013-203094

43. Zaber K, Śliwowska B, Jasiński T. Statin-induced autoimmune necrotizing myositis. Reumatologia 2015; 53: 341-4; https://doi.org/10.5114/reum.2015.57641

44. Kipfer S, Frigerio S, Hench J, et al. Immune-mediated necrotising myopathy linked to statin use. Lancet 2015; 386: e26; https://doi.org/10.1016/S0140-6736(15)60068-X

45. Shaver K, Sibley C. A case of mystery myopathy: An unexpected side effect of a frequently prescribed drug. Sakai.ohsu.edu Oregon Health Science University. Available at Sakai.Ohsu. edu/access/content/group/Shaver.pdf (last accessed September 2017)

46. Nichols L, Pfeifer K, Mammen AL, et al. An unusual case of statin-induced myopathy: AntiHMGCoA necrotizing autoimmune myopathy.J Gen Intern Med 2015; 30: 1879-83; https:// doi.org/10.1007/s11606-015-3303-9

47. Hinschberger O, Lohmann C, Lannes B, et al. Immune-mediated necrotizing myopathy associated with antibodies to hydroxy-methyl-glutaryl-coenzyme A reductase. Rev Med Interne 2014; 35: 546-9; https://doi.org/10.1016/j.revmed.2013.06.009

48. Ngo LQ, Wu AG, Nguyen MA, et al. A case report of autoimmune necrotizing myositis presenting as dysphagia and neck swelling. BMC Ear Nose Throat Disord 2016; 16: 7; https:// doi.org/10.1186/s12901-016-0027-3

49. Boyce B. 002. Case report: statin-induced autoimmune necrotizing myopathy with positive HMGCR antibodies. Rheumatology 2015; 54 (suppl 1): i50; http://dx.doi.org/10.1093/ rheumatology/kev088.002

50. Wongchawart M, Quinn R. Statin induced necrotizing myopathy. Proceeding of UCLA Healthcare 2016; 20

51. Curtin D, Costigan D, McCarthy C, et al. Novel antibody associations in immune-mediated necrotising myopathy without inflammation. Ir J Med Sci 2016; 185: 941-3; https://doi. org/10.1007/s11845-014-1207-z

52. Shagroni T, Park C, Rouah E, et al. Statin-associated autoimmune myopathy. Rheumatology 2017; 56: 1043-4; https://doi.org/10.1093/rheumatology/kew491

53. Marti J,Kolev I, Lorleac'h A, et al. Anti-HMG-CoA reductase necrotizing myopathy: A report of 4 cases. Rev Med Interne 2017; 38: 228-34; https://doi.org/10.1016/j.revmed.2016.10.384

54. McGrath NM, Turner CP. Isolated gluteal and paravertebral muscle weakness due to anti-3hydroxy-3-methylglutaryl-coenzyme a reductase antibody-associated necrotizing autoimmune myopathy. Muscle Nerve 2016; 54: 150-2; https://doi.org/10.1002/mus.25130

55. Watanabe Y, Suzuki S, Nishimura H, et al. Statins and myotoxic effects associated with anti3-hydroxy-3-methylglutaryl-coenzyme A reductase autoantibodies: an observational study in Japan. Medicine (Baltimore) 2015; 94: e416; https://doi.org/10.1097/MD.0000000000000416

56. Sweidan AJ, Leung A, Kaiser CJ, et al. A Case of Statin-associated autoimmune myopathy. Clin Med Insights Case Rep 2017; 10: 1179547616688231; https://doi.org/10.1177/1179547616688231

57. Oestmann A, Bründler J, Repond F. Invalidisierende muskelschwäche. Praxis 2017; 106: 45-7; https://doi.org/10.1024/1661-8157/a002576

58. Khan NAJ, Khalid S, Ullah S, et al. Necrotizing Autoimmune Myopathy: A rare variant of Idiopathic Inflammatory Myopathies. J Investig Med High Impact Case Rep 2017; 5: 2324709617709031; https://doi.org/10.1177/2324709617709031

59. Kuru S, Suzuki S, Ogata K, et al. Screening of autoantibodies associated with necrotizing myopathy among undiagnosed chronic myopathy. Rinsho Shinkeigaku 2017; 57:562-6; https:// doi.org/10.5692/clinicalneurol.cn-001075

60. Brannick B, Childress R. A case of HMGCR-antibodies causing statin-associated autoimmune necrotizing myopathy.J Clin Lipidol 2017; 11: 824; https://doi.org/10.1016/j.jacl.2017.04.086 
61. Pongpakdee S, Suzuki S, Tanboon J, et al. Immune-mediated necrotizing myopathy associated with anti HMGCR autoantibody: First case in Thailand. The 57th Annual Meeting of the Japanese Society of Neurology. https://doi.org/10.13140/RG.2.1.1024.2161

62. Garcì MB, Cook EA. Statin-induced necrotizing autoimmune myopathy. Proceedings of UCLA Healthcare 2017: 21

63. Horák T, Voháňka S, Tvrdíková E, et al. Statin-Induced Necrotizing Autoimmune Myopathy. Česká a slovenská neurologie a neurochirurgie 2017; 80/113: 569-77; https://doi.org/10.14735/ amcsnn2017569

64. Jackson EJ, Chafizadeh E, Pham A. Case study: Autoimmune-mediated necrotizing myositis due to statin therapy. Lipid Spin 2016; 14: 23-5

65. Ong SG, Ding HJ. Patient with statin-associated immune-mediated necrotizing myopathy presenting with subcutaneous edema, persistent bulbar weakness and absent anti-HMGCR. Int J Rheum Dis 2017; 20: 2175-8; https://doi.org/10.1111/1756-185X.12814

66. Ayesha SM, Meena AK, Vangala N, et al.Necrotizing Autoimmune Myopathy: Clinicopathologic study from a single tertiary care centre. Ann Indian Acad Neurol 2018; 21: 62-7

67. Giudizi MG, Cammelli D, Vivarelli E, et al. Anti-HMGCR antibody-associated necrotizing myopathy: diagnosis and treatment illustrated using a case report. Scand J Rheumatol 2016; 45: 427-9; https://doi.org/10.3109/03009742.2015.1132761

68. Ginanneschi F, Volpi N, Giannini F, et al. Rhabdomyolysis in an elderly multitreated patient: multiple drug interactions after statin withdrawal. J Neurol Sci 2014; 336: 284-7; https://doi. org/10.1016/j.jns.2013.10.040

69. Canzonieri E, De Candia C, Tarascio S, et al. A severe myopathy case in aged patient treated with high statin dosage. Toxicol Rep 2017; 4: 438-40; https://doi.org/10.1016/j.toxrep.2017.07.009

70. Ponzalino V, Bortolani S, Vercelli L, et al. Poster P22131 - Necrotizing myopathies: A single Centre experience. Eur J Neurol 2016; 23(Supp1.2): 552

71. Villa L, Peverelli L, Lerario A, et al. P.11 Statin-induced necrotizing autoimmune myopathy: clinical, hystopathological and radiological characterization of five patients. Proceedings of the XVII Congress of the Italian Association of Myology. Acta Myol 2017; 36: 113

72. Lilleker JB, Vencovsky J, Wang G, et al.; all EuroMyositis contributors. The EuroMyositis registry: an international collaborative tool to facilitate myositis research. Ann Rheum Dis 2018; 77: 30-9; https://doi.org/10.1136/annrheumdis-2017-211868

73. Nazir S, Lohani S, Tachamo N, et al. Statin-associated autoimmune myopathy: A systematic review of 100 cases. J Clin Rheumatol 2017; 23: 149-54; https://doi.org/10.1097/ RHU.0000000000000497

74. Kennedy N, Keating P, O'Donnell J. HMGCR-associated myositis: a New Zealand case series and estimate of incidence. Intern Med J 2016; 46: 622-5; https://doi.org/10.1111/imj.13023

75. Parikh P,Tavee J, Soltanzadeh P, et al.Anti-3-hydroxy-3-methylglutaryl-coenzyme a reductase autoantibody-positive necrotizing autoimmune myopathy with dermatomyositis-like eruption. Muscle Nerve 2018; 57: E135-E136; https://doi.org/10.1002/mus.26072

76. Liang E, Rastegar M.Immune-mediated necrotising myopathy: a rare cause of hyperCKaemia. BMJ Case Rep 2018; 2018: pii: bcr-2017-223870; https://doi.org/10.1136/bcr-2017-223870

77. Carvalho AAS, da Silva VG, Zanoteli E, et al. Myopathy due to HMGCR antibodies in adult mimicking muscular dystrophy associated with cancer and statin exposure - narrative review of the literature - case report. Ther Clin Risk Manag 2018; 14: 903-7; https://doi.org/10.2147/ TCRM.S162931

78. Karunaratne K, Amiras D, Pickering MC, et al. Autoimmune necrotising myopathy and HMGCR antibodies. Pract Neurol 2018; 18: 151-5; https://doi.org/10.1136/practneurol-2017-001848

79. Vithayathil M, Phung A. Near-fatal statin-associated autoimmune myositis.J Clin Neurol 2018; 14: 426-7; https://doi.org/10.3988/jen.2018.14.3.426

80. Aubignat $\mathrm{M}, \mathrm{Schmidt} \mathrm{J}$, Gourguechon $\mathrm{C}$, et al. Myopathies à anticorps anti-HMGCR : à propos de 5 cas. La Revue de Médecine Interne 2018; 39 (suppl 1): A227-A228; https://doi. org/10.1016/j.revmed.2018.03.225

81. Ge Y,Lu X, Peng Q, et al. Clinical characteristics of anti-3-hydroxy-3-methylglutaryl coenzyme A reductase antibodies in Chinese patients with Idiopathic Inflammatory Myopathies. PLoS One 2015; 10: e0141616; https://doi.org/10.1371/journal.pone.0141616

82. Navarro Pérez MP, Sanabria Sanchinel AA, Alfaro Torres J, et al. Autoimmune necrotising myopathy: A case report. Neurologia 2017; pii: S0213-4853(17)30195-0; https://doi. org/10.1016/j.nrl.2017.04.002 
83. Landon-Cardinal O, Allenbach Y, Benveniste O. Anti-HMGCR Necrotizing Autoimmune Myopathy leading to identification of cancer relapse. Clin Med Rev Case Rep 2017; 4: 164; https://doi.org/10.23937/2378-3656/1410164

84. Rankin W, Gabb G, Coates P. Serious statin-associated myositis in an Australian Aboriginal man. Pathology 2017; 49 (S1): S13-S17; https://doi.org/10.1016/j.pathol.2016.12.028

85. Allenbach Y, Keraen J, Bouvier AM, et al. High risk of cancer in autoimmune necrotizing myopathies: usefulness of myositis specific antibody. Brain 2016; 139(Pt 8): 2131-5; https:// doi.org/10.1093/brain/aww054

86. Kadoya M, Hida A, Hashimoto Maeda M, et al. Cancer association as a risk factor for antiHMGCR antibody-positive myopathy. Neurol Neuroimmunol Neuroinflamm 2016; 3: e290; https://doi.org/10.1212/NXI.0000000000000290

87. Tsujikawa K, Hara K, Muro Y, et al. HMGCR antibody-associated myopathy as a paraneoplastic manifestation of esophageal carcinoma. Neurology 2016; 87: 841-3; https://doi.org/10.1212/ WNL.0000000000003006

88. Yamaguchi T, Matsunaga A, Ikawa M, et al. A case of anti-3-hydroxy-3-methylglutarylcoenzyme A reductase antibody-positive paraneoplastic necrotizing myopathy associated with advanced gastric cancer that responded to intravenous immunoglobulin therapy. Rinsho Shinkeigaku 2017; 57: 118-23; https://doi.org/10.5692/clinicalneurol.cn-000982

89. Pinal-Fernandez I, Parks C, Werner JL, et al. Longitudinal course of disease in a large cohort of myositis patients with autoantibodies recognizing the signal recognition particle. Arthritis Care Res (Hoboken) 2017; 69: 263-70; https://doi.org/10.1002/acr.22920

90. Allenbach Y, Arouche-Delaperche L, Preusse C, et al. Necrosis in anti-SRP+ and antiHMGCR+myopathies: Role of autoantibodies and complement. Neurology 2018; 90: e507-e517; https://doi.org/10.1212/WNL.0000000000004923

91. Christopher-Stine L, Casciola-Rosen LA, Hong G, et al. A novel autoantibody recognizing $200-\mathrm{kd}$ and $100-\mathrm{kd}$ proteins is associated with an immune-mediated necrotizing myopathy. Arthritis Rheum 2010; 62: 2757-66; https://doi.org/10.1002/art.27572

92. Werner JL, Christopher-Stine L, Ghazarian SR, et al. Antibody levels correlate with creatine kinase levels and strength in anti-3-hydroxy-3-methylglutaryl-coenzyme A reductase-associated autoimmune myopathy.Arhtritis Rheum 2012; 64: 4087-93; https://doi.org/10.1002/art.34673

93. Musset L, Miyara M, Benveniste O, et al. Analysis of autoantibodies to 3-hydroxy-3methylglutaryl-coenzyme A reductase using different technologies.J Immunol Res 2014; 2014 : 405956; https://doi.org/10.1155/2014/405956

94. Drouot L, Allenbach Y, Jouen F, et al.; French Myositis Network [CN]. Exploring necrotizing autoimmune myopathies with a novel immunoassay for anti-3-hydroxy-3-methyl-glutaryl-CoA reductase autoantibodies. Arthritis Res Ther 2014; 16: R39; https://doi.org/10.1186/ar4468

95. Limaye V, Bundell C, Hollingsworth $\mathrm{P}$, et al. Clinical and genetic associations of autoantibodies to 3-hydroxy-3-methyl-glutaryl-coenzyme a reductase in patients with immune-mediated myositis and necrotizing myopathy. Muscle Nerve 2015; 52: 196-203; https://doi.org/10.1002/ mus. 24541

96. Shovman O, Gilburd B, Chayat C, et al. Anti-HMGCR antibodies demonstrate high diagnostic value in the diagnosis of immune-mediated necrotizing myopathy following statin exposure. Immunol Res 2017; 65: 276-81; https://doi.org/10.1007/s12026-016-8867-x

97. Mammen AL,Pak K, Williams EK, et al. Rarity of anti-3-hydroxy-3-methylglutaryl-coenzyme A reductase antibodies in statin users, including those with self-limited musculoskeletal side effects. Arthritis Care Res (Hoboken) 2012; 64: 269-72; https://doi.org/10.1002/acr.20662

98. Selva-O'Callaghan A, Alvarado-Cardenas M, Marin A, et al. Statins and myositis: the role of anti-HMGCR antibodies. Expert Rev Clin Immunol 2015; 11: 1277-9; https://doi.org/10.15 86/1744666X.2015.1102632

99. Betteridge ZE, Chinoy H, Jani M, et al. 055. Prevalence of autoantibodies to HMGCR in myositis patients. Rheumatology 2014; 53(suppl1): i54; https://doi.org/10.1093/rheumatology/ keu095.001

100. Liang WC, Uruha A, Suzuki S, et al. Pediatric necrotizing myopathy associated with anti-3hydroxy-3-methylglutaryl-coenzyme A reductase antibodies. Rheumatology (Oxford) 2017; 56: 287-93; https://doi.org/10.1093/rheumatology/kew386

101. Barbacki A, Fallavollita SA, Karamchandani J, et al. Immune-Mediated Necrotizing Myopathy and dietary sources of statins. Ann Intern Med 2018; 168: 893-904; https://doi.org/10.7326/ L17-0620

102. Tansley SL, Betteridge ZE, Simou S, et al.; Juvenile Dermatomyositis Research Group. AntiHMGCR autoantibodies in juvenile idiopathic inflammatory myopathies identify a rare but 
clinically important subset of patients.J Rheumatol 2017; 44: 488-92; https://doi.org/10.3899/ jrheum.160871

103. Kishi T, Rider LG, Pak K, et al.; for the Childhood Myositis Heterogeneity Study Group10. Anti-3-hydroxy-3-methylglutaryl-coenzyme A reductase autoantibodies are associated with DRB1*07:01 and severe myositis in pediatric myositis patients. Arthritis Care Res (Hoboken) 2017; 69: 1088-94; https://doi.org/10.1002/acr.23113

104. Mauhin W, Arouche-Delaperche L, Amelin D, et al. Les anticorps anti-HMGCoA-reductase associés aux myopathies nécrosantes auto-immunes ont une forte affinité pour l'HMGCoAreductase sans pour autant l'inhiber. La Revue de Médecine Interne 2017; 38(Suppl.1): a73; https://doi.org/10.1016/j.revmed.2017.03.059

105. Basharat P, Lahouti AH, Paik JJ, et al. Statin-induced anti-HMGCR-associated myopathy. $J$ Am Coll Cardiol 2016; 68: 234-5; https://doi.org/10.1016/j.jacc.2016.04.037

106. Troyanov Y, Landon-Cardinal O, Fritzler MJ, et al. Atorvastatin-induced necrotizing autoimmune myositis: An emerging dominant entity in patients with autoimmune myositis presenting with a pure polymyositis phenotype. Medicine (Baltimore) 2017; 96: e5694; https:// doi.org/10.1097/MD.0000000000005694

107. Balke M, Brunn A, Claeys KG, et al. Late onset necrotizing autoimmune myopathy 1 year after cessation of statin treatment. Acta Neurol Belg 2018; 7: 1-3; https://doi.org/10.1007/ s13760-018-0985-x

108. Eura N, Sugie K, Ozaki M, et al. Clinicopathological evaluation of anti-SRP versus antiHMGCR myopathy: What are the similarities and differences? J Neurol Sci 2017; 381 (Suppl. 15): 273-4; https://doi.org/10.1016/j.jns.2017.08.780

109. Bergua C, Chiavelli H, Simon JP, et al. Immune-mediated necrotizing myopathy. $Z$ Rheumatol 2016; 75: 151-6; https://doi.org/10.1007/s00393-015-0029-3

110. Pinal-Fernandez I, Mammen AL. Spectrum of immune-mediated necrotizing myopathies and their treatments. Curr Opin Rheumatol 2016; 28: 619-24; https://doi.org/10.1097/ BOR.0000000000000335

111. Watanabe Y, Uruha A, Suzuki S, et al. Clinical features and prognosis in anti-SRP and antiHMGCR necrotising myopathy.J Neurol Neurosurg Psychiatry 2016; 87: 1038-44; https://doi. org/10.1136/jnnp-2016-313166

112. Albayda J, Mammen AL. Is statin-induced myositis part of the polymyositis disease spectrum? Curr Rheumatol Rep 2014; 16: 433; https://doi.org/10.1007/s11926-014-0433-8

113. Morandi L, Angelini C, Prelle A, et al. High plasma creatine kinase: review of the literature and proposal for a diagnostic algorithm. Neurol Sci 2006; 27: 303-11; https://doi.org/10.1007/ s10072-006-0701-0

114. Oruch R, Pryme IF, Engelsen BA, et al. Neuroleptic malignant syndrome: an easily overlooked neurologic emergency. Neuropsychiatr Dis Treat 2017; 13: 161-75; https://doi.org/10.2147/ NDT.S118438

115. Berman BD. Neuroleptic malignant syndrome: a review for neurohospitalists. Neurohospitalist 2011; 1: 41-7; https://doi.org/10.1177/1941875210386491

116. Tse L, Barr AM, Scarapicchia V, et al. Neuroleptic Malignant Syndrome: A Review from a clinically oriented perspective. Curr Neuropharmacol 2015; 13: 395-406; https://doi.org/10.21 74/1570159X13999150424113345

117. Hama Y, Mori-Yoshimura M, Komaki H, et al. Childhood-onset anti-3-hydroxy-3methylglutaryl-coenzyme A reductase (anti-HMGCR) necrotizing myopathy needs to be distinguished from muscular dystrophy: A case study. Rinsho Shinkeigaku 2017; 57: 567-72; https://doi.org/10.5692/clinicalneurol.cn-001040

118. Mohassel P, Foley AR, Donkervoort S, et al. Anti-3-hydroxy-3-methylglutaryl-coenzyme a reductase necrotizing myopathy masquerading as a muscular dystrophy in a child. Muscle Nerve 2017; 56: 1177-81; https://doi.org/10.1002/mus.25567

119. Mammen AL. Which nonautoimmune myopathies are most frequently misdiagnosed as myositis? Curr Opin Rheumatol 2017; 29: 618-22; https://doi.org/10.1097/BOR.0000000000000441

120. Floyd JS, Brody JA, Tiniakou E, et al. Absence of anti-HMG-CoA reductase autoantibodies in severe self-limited statin-related myopathy. Muscle Nerve 2016; 54: 142-4. https://doi. org/10.1002/mus.25127

121. Mammen AL, Chung T, Christopher-Stine L, et al. Autoantibodies against 3-hydroxy-3methylglutaryl-coenzyme A reductase in patients with statin-associated autoimmune myopathy. Arthritis Rheum 2011; 63: 713-21; https://doi.org/10.1002/art.30156 